\title{
Avaliação do estado redox no sêmen humano e sua correlação com os parâmetros do espermograma
}

Adriana Patricia Laurenti Coelho

Ribeirão Preto

2014 


\section{ADRIANA PATRICIA LAURENTI COELHO}

\section{Avaliação do estado redox no sêmen humano e sua correlação com os parâmetros do espermograma}

Dissertação de Mestrado apresentada ao Programa de Pós-Graduação em Biociências Aplicadas à Farmácia para obtenção do Título de Mestre em Ciências.

Área de Concentração: Biociências Aplicadas à Farmácia

Orientadora: Profa. Dra. Cleni Mara Marzocchi Machado

Ribeirão Preto - SP

2014 


\section{AUTORIZO A REPRODUÇÃO E DIVULGAÇÃO TOTAL OU PARCIAL DESTE TRABALHO, POR QUALQUER MEIO CONVENCIONAL OU ELETRÔNICO, PARA FINS DE ESTUDO E PESQUISA, DESDE QUE CITADA A FONTE.}

Laurenti-Coelho, Adriana Patricia

Avaliação do estado redox no sêmen humano e sua correlação com os parâmetros do espermograma / Adriana Patricia Laurenti Coelho; orientadora Cleni Mara Marzocchi Machado. -- Ribeirão Preto, 2014.

82 f. : il.

Dissertação de mestrado -- Faculdade de Ciências Farmacêuticas de Ribeirão Preto/USP. Área de concentração: Biociências Aplicadas à Farmácia.

1. Sêmen humano 2. Estresse oxidativo 3. Espermograma 4. Estado redox. I. Título. II. Marzocchi-Machado, Cleni Mara. 


\section{FOLHA DE APROVAÇÃO}

Nome da aluna: Adriana Patricia Laurenti Coelho

Título do trabalho: Avaliação do estado redox no sêmen humano e sua correlação com os parâmetros do espermograma.

Dissertação de Mestrado apresentada ao

Programa de Pós-Graduação em Biociências Aplicadas à Farmácia para obtenção do Título de Mestre em Ciências.

Área de Concentração: Biociências Aplicadas à Farmácia

Orientadora: Profa. Dra. Cleni Mara Marzocchi Machado

Aprovado em:

Banca Examinadora

Prof. Dr: Instituição:

Julgamento: Assinatura:

Prof. Dr: Instituição:

Julgamento: Assinatura:

Prof. Dr: Instituição:

Julgamento: Assinatura: 
Dedico este trabalho a todos que me apoiaram e principalmente ao meu marido e aos meus filhos, pela compreensão e incentivo durante a realização deste trabalho. 


\section{AGRADECIMENTOS}

Agradeço a Deus pela vida e por todas as oportunidades de aprendizado que ela me traz.

À Profa. Dra. Cleni Mara Marzocchi Machado por me receber em seu laboratório e incentivar, ensinando sempre com dedicação e paciência.

Aos sujeitos voluntários que participaram desta pesquisa e que atenderam prontamente ao pedido de colaboração para a realização deste projeto.

Aos meus filhos, Thiago Laurenti Coelho e Lucas Laurenti Coelho; aos meus pais, Antonio Edson Laurenti e Maria Conceição Monteiro Laurenti; aos meus irmãos, Ana Paula Laurenti Gonçalves, Andréia Priscila Laurenti e Antonio Edson Monteiro Laurenti; aos meus sogros, Sylvio Coelho e Geralda Donzeli Coelho, pois o apoio da minha família sempre foi e será fundamental para a realização de qualquer projeto.

Ao meu marido, Marcelo Donzeli Coelho, por acreditar em mim e me apoiar nos momentos difíceis, me incentivando, com amor e dedicação.

Aos meus amigos do Laboratório de Análises Clínicas da Universidade de Ribeirão Preto pela torcida sincera e a compreensão nos muitos momentos de ausência para a realização deste estudo.

À minha amiga e sempre amiga Carla Denipotte Gallon Pitta pela sua amizade sincera e apoio durante todo este trabalho.

Ao farmacêutico-bioquímico José Eduardo Cavalcanti Del Lama, da Faculdade de Ciências Farmacêuticas de Ribeirão Preto-USP, pela ajuda sempre disposta na realização dos ensaios.

Ao doutorando Vinícius de Paula Venâncio, da Faculdade de Ciências Farmacêuticas de Ribeirão Preto-USP, pela valiosa parceria científica na padronização de métodos. 
Às amigas Juliana Escher Toller Kawahisa e Gisele Lelis da Silva, pela colaboração infinita em muitas etapas deste projeto.

À farmacêutica-bioquímica Ana Elisa Caleiro Seixas Azzolini, Depto. de Física e Química da da Faculdade de Ciências Farmacêuticas de Ribeirão Preto-USP, pela colaboração nos experimentos.

À biomédica Fabiana Rossetto de Morais, da Faculdade de Ciências Farmacêuticas de Ribeirão Preto-USP, pela realização das leituras das amostras no citômetro de fluxo.

As biólogas Maria Aparecida Carneiro Vasconcelos e Marilda Hatsumi Yamada Dantas, funcionárias do Setor de Reprodução Humana do HCFMRP-USP, pelo apoio técnico na realização dos espermogramas.

À Profa. Dra. Paula A. de Albuquerque Salles Navarro - HCFMRP-USP e ao Prof. Dr. Rui Alberto Ferriani - HCFMRP-USP por disponibilizarem a infraestrutura do seu departamento e pela parceria científica.

Aos docentes do programa de pós-graduação em Biociências Aplicadas à Farmácia da da Faculdade de Ciências Farmacêuticas de Ribeirão Preto-USP pelos seus ensinamentos.

Aos coordenadores e funcionários do programa de pós-graduação em Biociências Aplicadas à Farmácia da Faculdade de Ciências Farmacêuticas de Ribeirão Preto-USP pela atenção dispensada. 


\section{RESUMO}

Laurenti-Coelho AP. Avaliação do estado redox no sêmen humano e sua correlação com os parâmetros do espermograma [dissertação]. 2014. 82 f. Ribeirão Preto: Universidade de São Paulo, Faculdade de Ciências Farmacêuticas de Ribeirão Preto.

As espécies reativas de oxigênio (ERO) em baixos níveis são necessárias para as funções normais do espermatozoide, as quais estão envolvidas com a capacidade de fertilização. Entretanto, várias evidências demonstram que a produção excessiva de ERO leva ao estresse oxidativo, que por sua vez está relacionado à infertilidade masculina. Uma correlação positiva entre os níveis excessivos de ERO e concentrações anormais de espermatozoides, motilidade e morfologia tem sido descrita. Além disso, a capacidade antioxidante total do sêmen tem sido significativamente menor em casos de infertilidade comparado com casos férteis. $\mathrm{O}$ estresse oxidativo também tem sido relacionado ao envelhecimento e há evidências de que o acúmulo de radicais livres danifica o DNA do espermatozoide e prejudica a fertilização. A Organização Mundial da Saúde tem enfatizado a importância da avaliação do estresse oxidativo seminal e recomendado que cada laboratório estabeleça os valores de referência para os parâmetros do sêmen em sua população. O objetivo deste estudo foi avaliar o estado redox no sêmen humano e sua correlação com os parâmetros do espermograma. Para tanto, avaliou-se a medida de ERO (quimioluminescência, QL), a atividade antioxidante (QL e catalase), a peroxidação lipídica (malondialdeído, MDA), a medida dos produtos avançados de oxidação proteica (AOPP) e apoptose/necrose (anexina/iodeto de propídeo, citometria de fluxo) no sêmen humano de homens saudáveis e férteis (Controles; $n=7$ ). As metodologias foram padronizadas para aplicá-las à análise do sêmen de homens que estavam em investigação de infertilidade (Pacientes; n=23), e correlacionar os resultados com os parâmetros do espermograma. Os principais resultados mostraram 1) a medida de ERO no sêmen de Pacientes sem alterações no espermograma (Pacientes ${ }^{\mathrm{a}} ; \mathrm{n}=9$ ) foi maior do aquela para sêmen dos Pacientes com alterações no espermograma (Pacientes ${ }^{\mathrm{b}} ; \mathrm{n}=14$ ) e dos Controles, sugerindo comprometimento da qualidade do sêmen pelo aumento de ERO, mesmo com espermograma normal; 2) não houve diferenças entre os grupos quanto à peroxidação lipídica (MDA), aos AOPP, catalase e apoptose/necrose; 3) quanto às correlações entre os parâmetros analisados, observou-se: correlação positiva entre a medida de ERO no sêmen in natura e no sêmen lavado do grupo Pacientes, validando a utilização do sêmen in natura para esta metodologia; correlação positiva entre a medida de ERO in natura e a apoptose, número de espermatozoides e número de leucócitos somente para o grupo Pacientes ${ }^{\mathrm{b}}$; correlação entre a medida de ERO in natura e a motilidade progressiva somente para o grupo Controle; correlação entre apoptose e número de espermatozoides nos grupos Pacientes e Pacientes ${ }^{\text {a }}$; estes resultados mostram correlações particulares em cada grupo e correlações compartilhadas, que caracterizam Controles e Pacientes. O perfil da presença e da ausência destas correlações no grupo Controle pode estabelecer um padrão de referência para as análises do estresse oxidativo no sêmen. Os resultados poderão contribuir para a aplicação da medida das ERO e das suas correlações com parâmetros do espermograma na análise de rotina do sêmen humano, para a investigação da infertilidade e de patologias do sistema reprodutor masculino.

Palavras-chave: sêmen humano; estresse oxidativo; espermograma; estado redox. 


\begin{abstract}
Laurenti-Coelho AP. Evaluation of redox state in human semen and its correlation with semen parameters [dissertation]. 2014. 82 f. Ribeirão Preto: University of São Paulo, Faculty of Pharmaceutical Sciences of Ribeirão Preto.
\end{abstract}

Reactive oxygen species (ROS) at low levels are required for normal function of sperm, which are involved in fertilization capacity. However, evidences show that the excessive production of ROS leads to oxidative stress, which in turn is related to male infertility. A positive correlation between excessive levels of ROS and abnormal sperm concentration, motility and morphology has been described. Moreover, the total antioxidant capacity of the semen has been significantly lower in cases of infertility compared with fertile cases. Oxidative stress has also been associated with aging and there is evidence that the excess of free radicals damages the DNA of sperm and impairs fertilization. The World Health Organization has emphasized the importance of the evaluation of seminal oxidative stress and recommended that each laboratory establish reference values for the parameters of semen in their population. The aim of this study was to evaluate the redox state in human semen and its correlation with semen parameters. For this purpose, we evaluated the measurement of ROS (chemiluminescence, CL), the antioxidant activity (CL and catalase), lipid peroxidation (malondialdehyde, MDA), the advanced oxidation protein products (AOPP) and apoptosis / necrosis (annexin / propidium iodide flow cytometry) in semen of healthy, fertile men (Controls, $\mathrm{n}=7$ ). The methods were standardized to apply them to the analysis of semen of men who were in infertility investigation (Patients, $n=23$ ), and to correlate the results with the parameters of sperm. The main results showed: 1) the measurement of ROS in the semen of patients with normal semen (Patients ${ }^{\mathrm{a}}, \mathrm{n}=9$ ) was higher than that for semen of patients with abnormal semen analysis (Patients ${ }^{\mathrm{b}}, \mathrm{n}=14$ ) and Controls, suggesting impairment of the quality semen by increasing ROS, despite normal semen; 2) no differences were found among the groups regarding to lipid peroxidation (MDA), the AOPP, catalase and apoptosis / necrosis; 3) concerning the correlations among the parameters analyzed, we observed: positive correlation between the measurement of ROS in semen in natura and washed semen of Patients group, validating the use of semen in natura for this method; positive correlation between the measurement of ROS in semen in natura and apoptosis, number of spermatozoa and leukocytes only for the Patients ${ }^{\mathrm{b}}$ group; correlation between the measurement of ROS in semen in natura and progressive motility only for the Control group; correlation between apoptosis and number of spermatozoa in the groups Patients and Patients ${ }^{\mathrm{a}}$; these results show particular and shared correlations in each group, which characterize Controls and Patients. The profile of the presence and absence of these correlations in the Control group may establish a reference standard for the analysis of oxidative stress in the semen. These results may contribute to the use of the measurement of ROS and their correlations with semen parameters in routine analysis of human semen, for the investigation of infertility and disorders of the male reproductive system.

Keywords: human semen, oxidative stress, semen analysis, redox state. 


\section{RESUMEN}

AP Laurenti-Coelho. Evaluación del estado redox en el semen humano y su correlación con los parámetros del semen [disertación]. 2014. 82 f. Ribeirão Preto: Universidad de São Paulo, de la Facultad de Ciencias Farmacéuticas de Ribeirão Preto.

Se requieren especies reactivas de oxígeno (ERO) en niveles bajos para la función normal de los espermatozoides, que están implicados en la capacidad de fertilización. Sin embargo, varias líneas de evidencia demuestran que la producción excesiva de ERO conduce a estrés oxidativo, que a su vez está relacionado con la infertilidad masculina. Una correlación positiva entre los niveles excesivos de ERO y la concentración de esperma anormal, la motilidad y la morfología se han descrito. Por otra parte, la capacidad antioxidante total del semen ha sido significativamente menor en los casos de infertilidad en comparación con fértiles. El estrés oxidativo también se ha asociado con el envejecimiento y existe evidencia de que la acumulación de radicales libres dañan el DNA de esperma y afectar a la fertilización. La Organización Mundial de la Salud ha hecho hincapié en la importancia de la evaluación del estrés oxidativo seminal y recomienda que cada laboratorio establezca los valores de referencia para los parámetros del semen en su población. El objetivo de este estudio fue evaluar el estado redox en el semen humano y su correlación con los parámetros del análisis de semen. Con este fin, se evaluó la cantidad de ERO (quimioluminiscencia, QL), la actividad antioxidante (QL y catalasa), peroxidación de lípidos (malondialdehído, MDA), una medida de los productos de proteína de oxidación avanzada (AOPP) y la apoptosis / necrosis (Anexina / yoduro de propidio citometría de flujo) en el semen de hombres sanos, fértiles (Controles, $\mathrm{n}=7$ ). Las metodologías se estandarizaron para aplicarlos al análisis de semen de los hombres que estaban en la investigación de la infertilidad (Pacientes, $\mathrm{n}=23$ ), y correlacionar los resultados con los parámetros de análisis de semen. Los principales resultados mostraron 1) la cantidad de ERO en el semen de los pacientes con análisis de semen normal (Pacientes ${ }^{\mathrm{a}}, \mathrm{n}=9$ ) fue mayor que para el semen de los pacientes con análisis de semen anormal $\left(\right.$ Pacientes $^{\mathrm{b}}, \mathrm{n}=14$ ) y controles, lo que sugiere deterioro de la calidad del semen por el aumento de ERO incluso con semen normal; 2) no hubo diferencias entre los grupos con respecto a la peroxidación lipídica (MDA), la AOPP, catalasa y la apoptosis / necrosis; 3) En cuanto a las correlaciones entre los parámetros analizados, se observó: correlación positiva entre la cantidad de ERO en el semen in natura y se lavó el semen grupo de Pacientes, validando la uso de semen in natura a esta metodología; correlación positiva entre la cantidad de ERO en el sêmen in natura y la apoptosis, el número de espermatozoides y leucocitos sólo el grupo Pacientes ${ }^{\mathrm{b}}$; correlación entre la cantidad de ERO en el semen in natura y motilidad progresiva sólo para el grupo de Controles; correlación entre la apoptosis y el número de espermatozoides en los grupos de Pacientes y Pacientes ${ }^{\mathrm{a}}$; estos resultados muestran correlaciones privadas y compartidas en cada grupo, que caracterizan a los grupos de Controles y Pacientes. El perfil de la presencia y la ausencia de estas correlaciones en el grupo de Controles puede establecer un punto de referencia para el análisis de estrés oxidativo en el semen. Los resultados pueden contribuir a la aplicación de la cantidad de ERO y sus correlaciones con semen parámetros en el análisis rutinario de semen humano, para la investigación de la infertilidad y trastornos del sistema reproductor masculino.

Palabras clave: el semen humano; el estrés oxidativo; semen; estado redox. 


\section{LISTA DE ABREVIATURAS}

AOPP

DMSO

DNA

$\Delta \mathrm{DO}$

ERO

FITC

GPx5

G6PD

GR

GSH

GSSG

$\mathrm{HO}_{2}{ }^{\circ}$

$\mathrm{H}_{2} \mathrm{O}_{2}$

MDA

NAD(P)H

NADPH - oxidoredutase

NAD(P)H-oxidase

$\mathbf{O}_{2}$

$\mathrm{O}^{\circ-}$

$\mathrm{OH}^{\bullet}$

PI

PS

PBS
Produtos avançados de oxidação proteica

Dimetilsufóxido

Ácido desoxirribonucleico

Variação da densidade óptica

Espécie(s) Reativa(s) de Oxigênio

Isotiocianato de fluoresceína

Glutationa peroxidase 5

Glicose-6-fosfato desidrogenase

Glutationa redutase

Glutationa

Dissulfeto de glutationa

Hidroperoxila

Peróxido de hidrogênio

Malondialdeído

Nicotinamida dinucleotídeo fosfato reduzido

Nicotinamida dinucleotídeo fosfato oxidoredutase

Nicotinamida dinucleotídeo fosfato oxidase reduzida

Oxigênio molecular

Ânion superóxido

Radical hidroxil

Iodeto de propídio

Fosfatidilserina

Salina tamponada com fosfato $\mathrm{pH} 7,4$ 
QL

$\mathbf{r}$

RNA

SOD

TBA

TBARS
Quimioluminescência

Coeficiente de correlação de Pearson

Ácido ribonucleico

Superóxido dismutase

Ácido tiobarbitúrico

Substâncias reativas ao ácido tiobarbitúrico 


\section{SUMÁRIO}

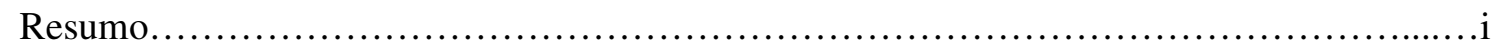

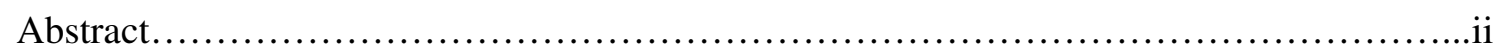

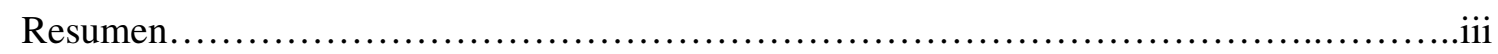

Lista de Figuras...............................................................

Lista de Tabelas.................................................................

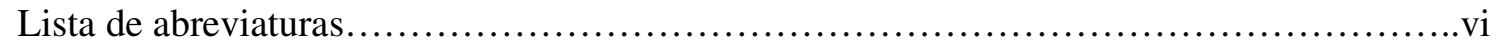

1 Introdução.................................................................... 18

1.1 Espécies Reativas de Oxigênio.............................................20

1.2 Via de Geração das ERO...................................................21

1.2.1 Via de Geração das ERO no Sêmen Humano....................................21

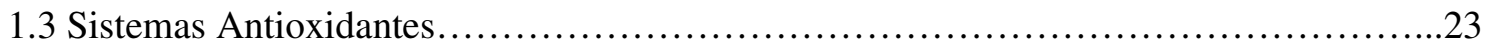

1.4 Efeitos do Estresse Oxidativo.................................................24

2 Justificativa............................................................... 29

3 Objetivos................................................................. 31

3.1 Objetivo Geral......................................................... 32

3.2 Objetivos Específicos.................................................. 32

4 Casuísticas e Métodos......................................................... 33

4.1 Casuística.............................................................. 34

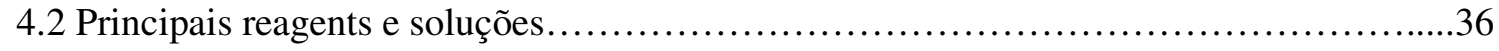

4.2 .1 Burst oxidativo.......................................................... 36

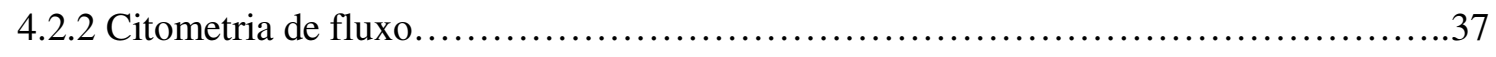

4.2.3 Pesquisa de leucócitos.................................................. 37

4.2.4 Produtos avançados de oxidação proteica.................................... 37 
4.2.5 Peroxidação lipídica. 37

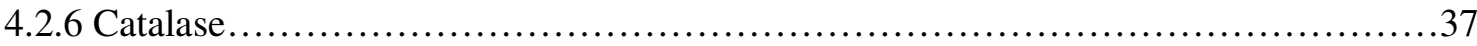

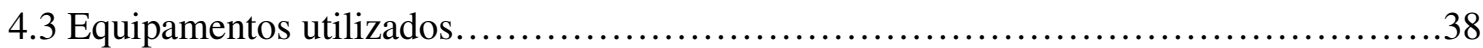

4.4 Processamento das amostras de semen......................................... 38

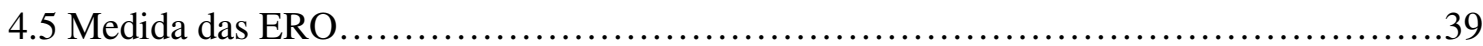

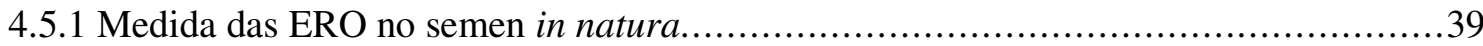

4.5.2 Medida das ERO na suspensão de espermatozoides $1,25 \times 10^{6} / \mathrm{mL}$ livre de plasma seminal. 39

4.5.3 Medida das ERO na suspensão de espermatozoides livre de plasma seminal com $\mathrm{n}^{\circ}$

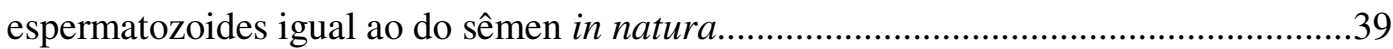

4.6 Pesquisa de leucócitos: identificação de granulócitos pelo teste de Endtz.........................40

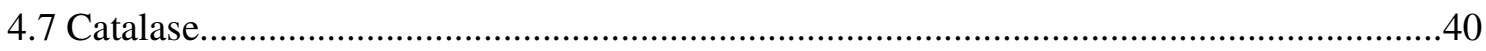

4.8 Avaliação da Peroxidação lipídica pelo Método TBARS.................................................41

4.9 Determinação dos produtos avançados de oxidação proteica (AOPP) ...............................41

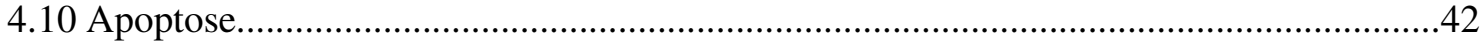

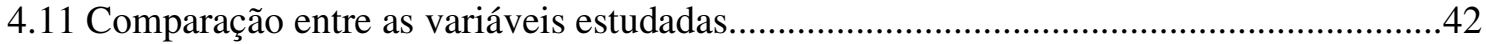

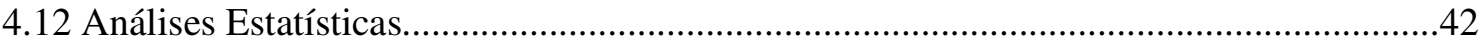

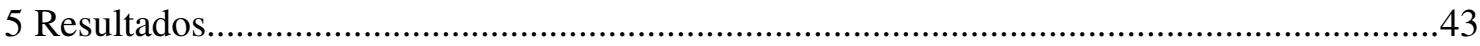

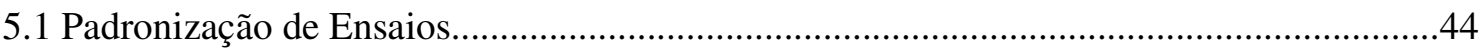

5.1.1 Padronização do Ensaio de determinação dos Produtos Avançados de Oxidação Protéica

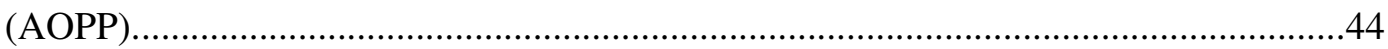

5.1.2 Padronização da Análise de Apoptose e Necrose no sêmen humano por citometria de

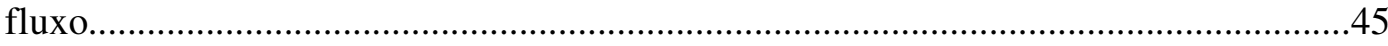

5.1.3 Padronização da Avaliação da Peroxidação lipídica pelo Método TBARS....................46

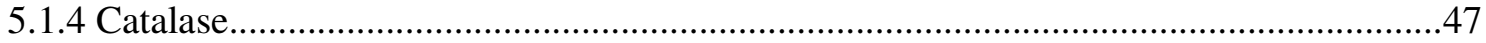

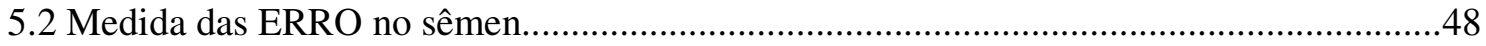

5.3 Capacidade do fluido seminal inibir as ERO................................................................... 51

5.4 Correlação das medidas de ERO no sêmen lavado e no sêmen in natura..........................51

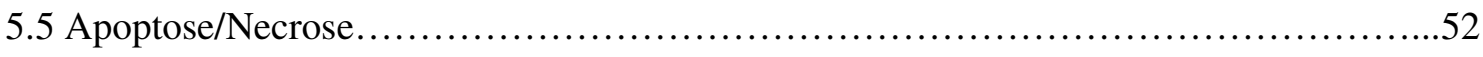

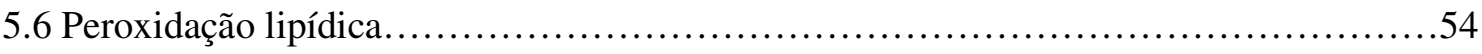

5.7 Produtos avançados de oxidação proteica............................................................................55

5.8 Catalase 
5.9 Coeficiente de correlação entre os parâmetros do espermograma, parâmetros do estado redox, apoptose e necrose nas amostras de sêmen....................................................................56

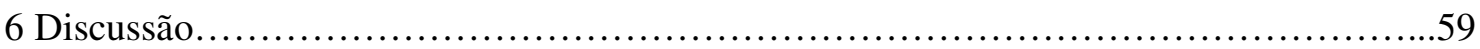

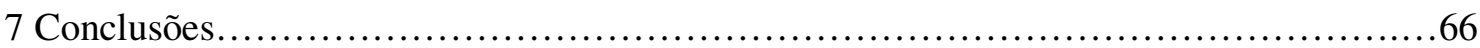

8 Referências Bibliográficas........................................................ 68

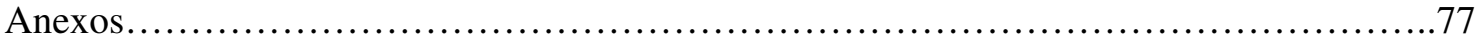

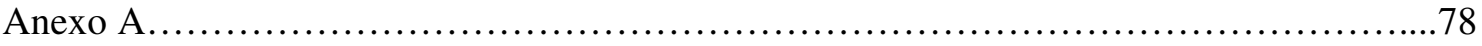

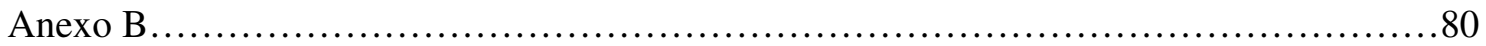


1.Introdução 
A infertilidade é uma condição que afeta cerca de $15 \%$ a $25 \%$ de todos os casais que tentam engravidar. A Organização Mundial da Saúde (WHO, 2010) define infertilidade como a incapacidade de casais sexualmente ativos, no mínimo três vezes por mês, alcançarem uma gravidez em pelo menos um ano, sem o uso de contraceptivos. A infertilidade é um fenômeno multifatorial que envolve homens e mulheres, sendo que em $50 \%$ dos casos, as causas são oriundas do homem (Trussell, 2013; WHO, 2010). O fator masculino é considerado envolvido no quadro de infertilidade do casal quando alterações na concentração espermática, motilidade e/ou morfologia estiver presente em pelo menos uma de duas análises seminais coletadas com intervalo de uma às quatro semanas (Agarwal et al., 2011). As anormalidades apresentadas nestes três parâmetros são definidas como oligospermia, quando a concentração espermática é menor que $15 \times 10^{6}$ espermatozoides/mL, astenospermia, quando apresenta motilidade menor que $40 \%$ e terastospermia para formas normais abaixo de 4\%. A azoospermia é uma condição menos frequente e se caracteriza pela ausência total de espermatozoides (Cooper et al., 2010; WHO, 2010). As causas da infertilidade masculina podem sem hormonais, traumas diretos, inflamações ou infecções nos testículos, varicocele, criptorquidismo, microdeleções do cromossomo-Y, câncer testicular e quimioterapia, disfunção erétil, ejaculação retrógrada, epididimite, ausência congênita bilateral dos vasos deferentes, síndrome de Klinefelter e síndrome das células de Sertoli (Wiser et al., 2012). Apesar da etiologia da infertilidade masculina ser multifatorial, aproximadamente 30 a $40 \%$ são classificadas como idiopáticas (Hellani et al., 2006). O diagnóstico de infertilidade idiopática masculina normalmente é estabelecido quando o critério da análise do sêmen é insuficiente para explicar a exata etiologia da doença ou se apresenta dentro dos valores normais (Kovac et al., 2013). O estresse oxidativo é considerado como uma causa importante e plausível para a infertilidade idiopática. A produção excessiva de espécies reativas de oxigênio (ERO) e o estresse oxidativo no sistema reprodutivo masculino são prejudiciais para o espermatozoide (Aziz et al., 2004) e tem sido associados com a diminuição da concentração, motilidade e morfologia (Khosrowbeygi; Zarghami, 2007). Aproximadamente 30 a $40 \%$ dos homens com infertilidade idiopática apresentam níveis significativamente mais elevados de ERO no sêmen além da diminuição das propriedades antioxidantes quando comparados aos homens saudáveis ( Lanzafame et al, 2009).

As ERO podem exercer papéis benéficos ou deletérios aos organismos. A produção de ERO e os sistemas antioxidantes são de extrema importância para o equilíbrio do estado redox nos organismos aeróbicos, sendo este, o equilíbrio entre a quantidade de ERO gerada e a quantidade removida pelo sistema antioxidante. Os efeitos benéficos das ERO ocorrem em 
concentrações baixas ou moderadas e envolvem respostas fisiológicas e celulares tais como defesa contra patógenos, sinalização celular e indução da mitose. No entanto, a produção excessiva de ERO pode não ser efetivamente controlada pelo sistema de defesa antioxidante e levar ao estresse oxidativo, um processo deletério que pode ser um mediador do dano às estruturas celulares, incluindo lipídios, proteínas e DNA levando à ruptura celular (Valko et al., 2007).

No trato genital masculino, as ERO em baixos níveis são necessárias para as funções normais do espermatozoide, incluindo capacitação, reação acrossomal, hiperativação, motilidade e fusão do oócito-espermatozoide (Aitken et al., 2010; Agarwal et al, 2012).

\subsection{Espécies Reativas de Oxigênio}

As espécies químicas na forma de radicais livres centradas no oxigênio são de grande interesse na área biológica porque a partir delas podem ser geradas espécies reativas, envolvendo outros átomos. O conhecimento sobre os radicais livres iniciou-se com a identificação de enzimas cujos substratos são radicais livres (McCord; Fridovich, 1969) seguindo para a identificação de vias metabólicas geradoras de tais espécies (Turrens; Boveris, 1980), a detecção de efeitos celulares e teciduais deletérios quando os radicais livres estão em concentrações aumentadas no meio fisiológico (Freeman; Crapo, 1982), a associação dos radicais livres com condições patológicas (Sies, 1985) e a participação de espécies reativas em vias de sinalização celular (Haddad, 2002).

A definição para radical livre é "espécie que tem um ou mais elétrons desemparelhados" a qual engloba o átomo de hidrogênio, com um elétron desemparelhado, a maioria dos metais de transição e o oxigênio molecular (Halliwell; Gutteridge, 1990).

As espécies reativas de oxigênio (ERO) são as espécies radicais livres ou radicalares, como o superóxido $\left(\mathrm{O}_{2}{ }^{--}\right)$e o radical hidroxil $\left(\mathrm{OH}^{*}\right)$ e outras que não possuem elétrons desemparelhados ou não radicalares como o peróxido de hidrogênio $\left(\mathrm{H}_{2} \mathrm{O}_{2}\right)$, mas que são muito reativas em decorrência de sua instabilidade, sendo a terminologia mais utilizada para definir radical livre (Bergendi et al., 1999). A alta reatividade das ERO permite a reação com as moléculas mais próximas, tornando estas em novos radicais livres, iniciando uma reação em cadeia, com rápida oxidação de biomoléculas vizinhas, podendo alterar o funcionamento normal das células ao redor (Warren et al., 1987).

Em condições de normalidade do metabolismo celular aeróbico, o oxigênio molecular $\left(\mathrm{O}_{2}\right)$ sofre redução tetravalente, com aceitação de quatro elétrons, resultando na formação de 
$\mathrm{H}_{2} \mathrm{O}$. Durante esse processo, são formados intermediários reativos como: os radicais $\mathrm{O}_{2}{ }^{\circ-}$, hidroperoxila $\left(\mathrm{HO}_{2}{ }^{\circ}\right)$ e $\mathrm{OH}^{*}$, e o não radical $\mathrm{H}_{2} \mathrm{O}_{2}$; (Ferreira; Matsubara, 1997; Halliwell; Gutteridge, 1999; Nordberg; Arnér, 2001).

\subsection{Via de Geração das ERO}

$\mathrm{O}$ ânion $\mathrm{O}_{2}{ }^{-}$é formado a partir da redução univalente do oxigênio molecular, caracterizada pela adição de um elétron. É gerado de forma espontânea, especialmente na membrana mitocondrial, através da cadeia respiratória e também por flavoenzimas, lipoxigenases e cicloxigenases. É um radical pouco reativo e não tem a habilidade de penetrar nas membranas lipídicas, agindo apenas no compartimento onde é produzido (Nordberg e Arnér, 2001).

$\mathrm{O}$ radical $\mathrm{OH} \bullet$ é considerado o radical livre mais reativo em sistemas biológicos, sendo capaz de causar mais danos do que qualquer outra ERO. É formado a partir do peróxido de hidrogênio, em uma reação catalisada por íons metais $(\mathrm{Fe}++o u \mathrm{Cu}+)$, denominada reação de Fenton (Ferreira; Matsubara, 1997; Halliwell; Gutteridge, 1999; Nordberg; Arnér, 2001). Reage rapidamente com biomoléculas e pode desencadear a peroxidação dos lipídios nas membranas celulares (Halliwell; Gutteridge, 1999).

$\mathrm{O}_{2} \mathrm{O}_{2}$ não é um radical livre, mas um metabólito do oxigênio extremamente deletério porque participa como intermediário na reação que produz o radical $\mathrm{OH} \bullet$. É gerado a partir da dismutação enzimática do $\mathrm{O}_{2}{ }^{-*}$ pela superóxido dismutase, tem vida longa e é capaz de atravessar membranas biológicas (Ferreira; Matsubara, 1997; Nordberg; Arnér, 2001).

\subsubsection{Via de Geração das ERO no Sêmen Humano}

O sêmen humano pode apresentar alguns tipos de células, incluindo células epiteliais, células redondas provenientes de vários estágios da espermiogênese, leucócitos, espermatozoides maduros e imaturos. Destas células, os leucócitos e espermatozoides imaturos, morfológica ou funcionalmente anormais, são reconhecidos como os maiores produtores de ERO. Também o excesso residual de citoplasma, proveniente de uma espermiogênese ineficiente está positivamente relacionado com a geração de ERO através do mecanismo mediado pela enzima G6PD citosólica. $\mathrm{O}_{2}{ }^{\circ-}$, o $\mathrm{H}_{2} \mathrm{O}_{2}$ e o $\mathrm{OH} \bullet$ são as ERO mais comumente geradas pelo espermatozoide, sendo que os espermatozoides imóveis e anormais geram uma quantidade muito maior de ERO que os normais (De Lamirande; Gagnon, 1993; Aitken, 1995;). Assim, o alto nível de ERO no plasma seminal de homens inférteis, quando 
comparado ao de homens férteis, não se deve à deficiência de enzimas antioxidantes como a superóxido dismutase (SOD) e /ou catalase, mas se dá pela produção excessiva de ERO pelos espermatozoides anormais (Zini et al., 2000).

Os espermatozoides produzem ERO através do seu metabolismo normal. Apesar do mecanismo bioquímico responsável pela produção das ERO pelo espermatozoide não estar completamente elucidado, existem evidências da presença de uma oxidase na membrana plasmática do espermatozoide que, quando ativada, gera $\mathrm{O}_{2}$ tendo como principal fonte de elétrons a nicotinamida nucleotídeo fosfato $\mathrm{NAD}(\mathrm{P}) \mathrm{H}$ responsáveis pela produção de $\mathrm{O}_{2}{ }^{*}$ pelo espermatozoide humano tendo o envolvimento do sistema NAD(P)H-oxidase (Aitken, 1995). Esta hipótese sugere que o $\mathrm{H}_{2} \mathrm{O}_{2}$ atravessa a membrana para o interior da célula e inibe a atividade de enzimas vitais como a glicose-6-fosfato desidrogenase (G6PD) através da via alternativa da hexose monofosfato, responsável pelo controle da disponibilidade intracelular de NADPH e o fluxo de glicose (Aitken et al., 1997). Porém, a hipótese de que a enzima espermática é similar à NADPH-oxidase foi rejeitada por De Lamirande e Lamothe (2009) porque não foram encontrados componentes desta enzima em espermatozoides testados por imuno blotting, contudo, a presença de uma enzima oxidase não identificada foi confirmada como responsável pela produção de $\mathrm{O}_{2}$ no espermatozoide. Outra hipótese da produção de ERO pelos espermatozoides é a do sistema NADPH - oxidoredutase dependente (diaforase) localizada na peça intermediária do espermatozoide e que está integrada no sistema respiratório da mitocôndria do espermatozoide (Gavella; Lipovac, 1992). A predominância da diaforase espermática como sistema gerador de ERO pelo espermatozoide foi sugerida por Plante et al. (1994) que observaram que apenas um terço das ERO produzidas pelo espermatozoide são liberadas para fora da célula e tem menos chance de atingir o espaço extracelular. O sistema mitocondrial é reconhecido como a maior fonte geradora de ERO na membrana interna de espermatozoides de homens inférteis, onde ocorre a fosforilação oxidativa (Wang et al., 2003).

Os processos inflamatórios também contribuem para o estresse oxidativo no sêmen. A principal fonte endógena de ERO no sêmen são os leucócitos, principalmente neutrófilos e macrófagos, e espermatozoides anormais (Aitken et al., 1994). A capacidade dos leucócitos de produzirem ERO depende da sua ativação que pode ocorrer em resposta a uma variedade de estímulos como inflamação ou infecção (Pasqualotto, 2000).O estresse oxidativo causado pela presença de leucócitos pode ter origem em uma infecção crônica ou epididimal e pode ser associada a uma significante indução ao dano do DNA do espermatozoide (Alvarez et al., 2002). Os leucócitos estão presentes no sêmen tanto de homens férteis quanto de homens 
inférteis, mesmo na ausência de processos infecciosos. A Organização Mundial da Saúde (WHO, 2010) define leucocitospermia como >1 milhão de leucócitos/mL de sêmen e esta quantidade de leucócitos tem sido considerada como presuntiva de uma infecção. Entretanto, Lackner et al. (2006) identificaram bactérias patogênicas em homens assintomáticos na ausência de leucocitospermia. Também tem crescido a evidência de que baixas concentrações de leucócitos são igualmente prejudiciais para a qualidade do sêmen e para a fertilidade. A porcentagem de espermatozoides morfologicamente normais varia inversamente com a concentração de leucócitos, utilizando-se um valor de 0,5 milhões de leucócitos/mL para a comparação (Thomas et al, 1997). Sharma et al. (2001) relataram que baixas concentrações de leucócitos, 0,1 x $10^{6}$ leucócitos/ mL, estão associadas com nível elevados de ERO e aumento ao dano do DNA.

\subsection{Sistemas Antioxidantes}

Embora as ERO em baixas concentrações tenham um papel importante na fisiologia e aquisição da capacidade de fertilização do espermatozoide, várias evidências demonstram que a produção excessiva de ERO está relacionada à infertilidade masculina. Uma correlação positiva entre os níveis excessivos de ERO e concentrações anormais de espermatozoides, motilidade e morfologia tem sido descrita (Agarwal et al., 1994; Venkatesh et al., 2009; Saalu, 2010). Além disso, a capacidade antioxidante total do sêmen tem sido significativamente menor em casos de infertilidade comparado com casos férteis (Venkatesh et al., 2009).

A diminuição da capacidade antioxidante do sêmen é tão importante quanto o aumento das ERO. O sistema reprodutivo, incluindo o plasma epididimal e seminal, contém poderosas moléculas antioxidantes enzimáticas e não enzimáticas que agem mantendo as concentrações de ERO em níveis baixos e protegendo o espermatozoide contra os metabólitos tóxicos do oxigênio (Agarwal et al., 2012). Estes antioxidantes podem agir tanto removendo o agente oxidante antes que este cause a lesão quanto reparando a lesão provocada (Ferreira; Matsubara, 1997; Halliwell; Gutteridge, 1999). As enzimas superóxido dismutase (SOD), catalase, glutationa peroxidase $5(\mathrm{GPx} 5)$ e gluttiona redutase (GR), presentes no plasma seminal, fazem parte deste sistema antioxidante enzimático que formam a primeira linha de defesa, atuando como redutores na prevenção da formação das ERO e protegendo os espermatozoides dos efeitos tóxicos do oxigênio (Chabory et al., 2009). As moléculas de baixo peso molecular também presentes no plasma seminal como a vitamina $\mathrm{C}, \mathrm{E}$, glutationa (GSH), carotenoides, flavonoides, albumina e ácido úrico fazem parte do sistema antioxidante 
não enzimático. Estes agem prevenindo a formação das ERO e removendo aquelas já formadas (Thiele et al., 1995). O espermatozoide possui um sistema de defesa antioxidante enzimático formado pelas enzimas SOD, catalase, GPx5 e GR (Aitken, 1995). A SOD presente no citoplasma e na mitocôndria remove o $\mathrm{O}_{2}{ }^{\bullet-}$ através da dismutação de duas moléculas de $\mathrm{O}_{2}{ }^{*-}$ em uma de $\mathrm{H}_{2} \mathrm{O}_{2}$, enquanto a catalase e a GPx5 detoxificam o $\mathrm{H}_{2} \mathrm{O}_{2}$ intra e extracelular catalisando a redução do $\mathrm{H}_{2} \mathrm{O}_{2}$ em $\mathrm{H}_{2} \mathrm{O}$ e $\mathrm{O}_{2}$ (Nordberg; Arnér, 2001). A

glutationa é o maior tiol antioxidante e tampão redox da célula (Masella et al., 2005). É um tripeptídio não protéico, presente tanto no estado reduzido (GSH) quanto no oxidado, o dissulfeto de glutationa (GSSG), cujos níveis são mantidos por duas enzimas, a glutamato cisteína ligase e a glutationa sintetase, e é responsável pela neutralização de $\mathrm{H}_{2} \mathrm{O}_{2}$ e proteção celular contra o estresse oxidativo. A GSH é abundantemente encontrada no citosol, núcleo e mitocôndrias. Sua presença no núcleo mantém o estado redox de proteínas sulfidril necessárias à reparação e expressão do DNA. Sua forma oxidada é acumulada no interior da célula e a medida de GSH/ GSSG é uma boa maneira de se medir o estresse oxidativo no organismo (Nogueira et al., 2004).

\subsection{Efeitos do Estresse Oxidativo}

$\mathrm{O}$ estresse oxidativo tem potencial efeito tóxico na qualidade e na função do espermatozoide. A extensão do dano induzido ao espermatozoide depende da natureza, da quantidade e da duração da exposição ao excesso de ERO. Fatores extracelulares como temperatura, tensão de oxigênio e composição do meio ambiente também são significativas (Gharagozloo; Aitken, 2011). Outros fatores que levam à uma diminuição da qualidade do sêmen são a exposição ocupacional aos agentes industriais, radiação, metais pesados e estilo de vida com fatores de risco como fumo, álcool e cafeína (Aitken et al., 2004). Estudo recente encontrou uma associação do fumo com um aumento de $48 \%$ da concentração de leucócitos no sêmen. Além disso, homens inférteis fumantes apresentam níveis de OS maiores do que homens inférteis não fumantes (Saleh et al., 2002b).

O estresse oxidativo é uma das maiores causas de infertilidade masculina e $30 \%$ a $40 \%$ dos homens inférteis apresentam níveis elevados de ERO no plasma seminal (Lanzafame et al., 2009). O espermatozoide foi o primeiro tipo celular ao qual foi atribuída uma potencial suscetibilidade ao OS e a sua incapacidade de reparar os danos causados pelos oxidantes devido à ausência de um sistema de reparação enzima-citoplasmática (Saleh; Agarwal, 2002a). Estresse oxidativo afeta o espermatozoide em três vias diferentes - a peroxidação lipídica, dano ao DNA e indução da apoptose (Agarwal et al., 2003; Hamada, 2012). Todos os 
componentes celulares incluindo lipídios, proteínas, ácidos nucleicos e açúcares são alvos do estresse oxidativo. A grande quantidade de ácidos graxos poliinsaturados presente na membrana plasmática do espermatozoide e as baixas concentrações de enzimas removedoras de ERO em seu citoplasma oferecem um mecanismo de defesa limitado contra o ataque oxidativo em seu DNA (Agarwal et al., 2002). Há evidências de que o acúmulo de radicais livres danifica o DNA do espermatozoide e prejudica o potencial de fertilização (Desai et al., 2009). Vários são os danos ao DNA do espermatozoide causados pelas ERO: cross-linking da cromatina, deleção de cromossomo, quebra da fita de DNA, oxidação de bases, particularmente a guanina, e indução de apoptose (Said et al., 2004). Esses danos estão ligados a baixos índices de fertilização, desenvolvimento embrionário prejudicado, abortos, defeitos congênitos e manifestações de diversas formas de morbidade nos descendentes, incluindo autismo e câncer infantil (Sukcharoen et al., 1995).

Em condições fisiológicas cerca de 1-3\% das moléculas de oxigênio nas mitocôndrias são convertidas em $\mathrm{O}_{2}{ }^{\circ}$, sendo este considerado uma ERO primária, que pode interagir com outras moléculas como precursor para a formação de uma sequência de ERO. Desta forma, no espermatozoide qualquer excesso de ERO tem o DNA mitocondrial como alvo imediato da ação deletéria dos radicais de oxigênio (Cadenas; Davies, 2000). É possível reparar muitos danos causados ao DNA nuclear, entretanto, o DNA mitocondrial não é corrigido facilmente. Por conseguinte, danos extensos ao DNA mitocondrial podem se acumular ao longo do tempo e desativar as mitocôndrias, causando a sua morte através do processo de apoptose (Valko et al., 2007). Isto afeta a viabilidade do espermatozoide. Os espermatozoides anormais e senescentes são eliminados por apoptose, uma resposta não inflamatória do tecido danificado caracterizada por uma série de mudanças morfológicas e bioquímicas. A apoptose tem um importante papel no controle do número das células germinativas e 50 a $70 \%$ dessas células passarão por este processo em diferentes estágios da espermatogênese. Entretanto, alguns fatores externos podem levar à um aumento da apoptose como exposição à radiação e a presença de $\mathrm{H}_{2} \mathrm{O}_{2}$ (Kesari, 2010). Este processo é específico e restrito às células germinativas no túbulo seminífero (Billing et al., 1995). Altas concentrações de ERO rompem as membranas internas e externas mitocondriais e liberam a proteína citocromo c, ativando as caspases e levando à apoptose (Sakkas et al., 1999). A presença da fosfatidilserina (PS), um marcador apoptótico, tem sido confirmada no espermatozoide durante o processo de apoptose. A PS é um fosfolipídio presente geralmente em maior quantidade no folheto interno da membrana plasmática celular e juntamente com uma grande variedade de fosfolipídios definem a fluidez desta (Chaurio et al., 2009). A apoptose causa através de alterações 
bioquímicas a translocação da PS para o folheto externo da membrana plasmática e que, quando exposta, atua como sinal de reconhecimento para os macrófagos que expressam receptores para PS, promovendo assim a eliminação das células apoptóticas (Lahorte et al., 2004). Aproximadamente $20 \%$ dos espermatozoides ejaculados estão em apoptose, indicado pela presença de resíduos de PS ligados à anexina V (Oosterhuis et al., 2000).

Durante a espermatogênese, o espermatozoide realiza a exclusão do seu citoplasma para se preparar para a fertilização. Entretanto, a geração excessiva de ERO frequentemente envolve um erro neste processo que resulta na liberação pelo epitélio germinativo de espermatozoides com citoplasma residual em excesso. Este citoplasma ativa o sistema NADPH principalmente pela via da hexose monofosfato gerando mais ERO e por consequência o estresse oxidativo (Rengan et al., 2012). Os efeitos para o espermatozoide são perda da motilidade, morfologia anormal e diminuição do potencial de fertilização, o que pode levar ao quadro de infertilidade masculina (Hampl et al., 2012).

A membrana plasmática do espermatozoide é composta por altos níveis de lipídios na forma de ácidos graxos poliinsaturados. Esses lipídios contêm duas ou mais duplas ligações carbono-carbono separadas por grupos metileno e são responsáveis pela fluidez da membrana plasmática e pelas mudanças que ocorrem durante a capacitação no trato reprodutor feminino (Sanocka; Kurpisz, 2004). A geração excessiva de ERO por espermatozoides resulta em peroxidação dos ácidos graxos poliinsaturados na sua membrana plasmática e mitocondrial conhecida como peroxidação lipídica (Pasqualotto et al., 2001), uma reação em cadeia que passa pelas etapas de iniciação, propagação e terminação. A iniciação se dá através do ataque a um lipídio por uma ERO, a qual sequestra um átomo de hidrogênio de um grupo metileno. O segundo passo, a propagação, é a formação de um radical lipídico alquil seguido por uma rápida reação com oxigênio formando um radical lipídico peroxila. O radical peroxil é capaz de retirar um átomo de hidrogênio dos ácidos graxos insaturados formando um radical lipídico e o hidroperóxido lipídico. Seu término ocorre com a propagação dos radicais lipídicos e peroxila até destruírem à si próprios (Tremellen, 2008). A peroxidação lipídica leva à ruptura da fluidez da membrana, diminuição da motilidade e prejuízo aos eventos de fusão da membrana como reação acrossômica e fusão espermatozoide-oócito. A motilidade é afetada devido a diminuição da fosforilação da proteina axonemal, enquanto a viabilidade diminui em consequência de importante modificação nas proteínas de membrane e reação acrossômica anormal que compromete a habilidade do espermatozoide de se fundir ao oócito (Gharagozloo; Aitken, 2011; Zini et al., 2010). 
Sendo a peroxidação lipídica uma reação autocatalítica associada com a fertilização anormal e um processo que também resulta na amplificação e exacerbação de todos problemas associados, torna-se crítica a compreeenssão do mecanismo deste processo (Tremellen, 2008; Agarwal et al., 2012). Um dos produtos da peroxidação lipídica é o malondialdeído (MDA) formado na etapa de terminação da reação em cadeia e pode se combinar com vários grupos moleculares, incluindo proteínas, lipoproteínas, RNA e DNA e também pode ter efeitos citotóxicos no espermatozoide. O MDA tem sido usado em vários ensaios bioquímicos para monitorar o dano peroxidativo causado ao espermatozoide, relacionando os resultados com a motilidade e capacidade de fusão do esperma-oócito (Sanocka; Kurpisz, 2004).

A medida de produtos avançados de oxidação proteica (AOPP) tem sido descrita como um marcador de estresse oxidativo para estimar o dano oxidativo à proteína e prever a eficácia potencial de estratégias terapêuticas destinadas a reduzir o estresse oxidativo (Witko-Sarsat et al., 1996; Selmeci, 2011). Os AOPP são derivados de proteínas altamente oxidadas, em especial a albumina, o fibrinogênio e lipoproteínas. O estresse oxidativo é o principal elemento nesta modificação e a mais importante é o sistema de mieloperoxidase $/ \mathrm{H}_{2} \mathrm{O}_{2} /$ haleto. Recentemente, o fibrinogênio oxidado tem sido indicado como a molécula-chave responsável para os AOPP no plasma humano. Assim, a albumina e o fibrinogênio podem ser considerados como componentes do sistema antioxidante do plasma. Uma vez que o fibrinogénio é um reagente de fase aguda, torna-se evidente que, durante cada episódio de resposta inflamatória, a capacidade antioxidante do plasma é aumentada. Fisiologicamente, AOPP são formados durante toda a vida, em pequenas quantidades e aumentam com a idade. Concentrações significativamente mais elevadas de AOPP são observadas em vários estados patológicos, tais como diabetes, aterosclerose, falência renal crônica, colite ulcerativa (Kalousová et al., 2005; Alagozlu et al., 2013). Desta forma, os AOPP são reconhecidos como marcadores de dano oxidativo das proteínas, intensidade de estresse oxidativo e inflamação.

O estresse oxidativo também tem sido relacionado ao envelhecimento, mostrando que os níveis de ERO são significativamente maiores no sêmen de homens com idade superior a 40 anos (Cocuzza et al., 2008). Apesar de poucos casos, estudos indicam que os homens começam a contribuir para um declínio na fertilidade do casal por volta dos trinta anos de idade e para a diminuição da fecundidade em torno dos quarenta anos. Com o aumento da idade, os níveis de testosterona começam a diminuir resultando em hipogonadismo. Entretanto, se a testosterona é usada como tratamento para o hipogonadismo, esta pode suprimir a espermatogênese (Stewart; Kim, 2011). Nas últimas décadas vários estudos têm 
sugerido uma redução da qualidade do sêmem com o aumento da idade (Cocuzza et al., 2008; Angelopoulou et al., 2009; Desai et al., 2010). À partir dos 35 anos, alguns parâmetros como volume, morfologia e motilidade podem apresentar-se anormais (Stewart, 2011; Kimberly et al., 2012). Após os quarenta anos, pode ocorrer no sêmen um aumento do dano ao DNA. Todavia, o fator idade no sexo masculino é menos importante do que no sexo feminino, mas se torna especialmente importante quando a parceira também possui idade avançada (Desai et al., 2009).

O diagnóstico da infertilidade masculina é feito através do espermograma que avalia vários parâmetros incluindo volume, cor, $\mathrm{pH}$, tempo de liquefação, viscosidade, concentração espermática, morfologia, concentração de células redondas e vitalidade (WHO, 2010). Além desta avaliação de rotina, muitos testes avançados podem ser utilizados como ferramentas para estabelecer as causas da infertillidade masculina, entre eles a avaliação dos níveis de ERO, a capacidade antioxidante total e o nível de fragmentação do DNA, compactação do DNA e apoptose, além da presença e localização de anticorpos antiespermáticos e testes genéticos (Kovac et al., 2013). A Organização Mundial da Saúde (WHO, 2010) tem defendido a importância da avaliação do estresse oxidativo seminal e recomendado que cada laboratório estabeleça os valores de referências para os parâmetros normais do sêmen em sua população (Athayde et al., 2007). 
7. Conclusões 
- Validação da medida das ERO por quimiolumescência no sêmen in natura;

- Validação da amostra de sêmen in natura para os ensaios de medida de ERO por quimioluminescência devido à correlação positiva entre a medida de ERO no sêmen in natura e no sêmen lavado do grupo Pacientes;

- Caracterização de correlações particulares e compartilhadas pelos grupos Pacientes, com espermograma normal e com espermograma anormal, e Controles entre os parâmetros do espermograma e de estado redox que definem um perfil de referência para amostras controles e de pacientes:

- correlação positiva entre a medida de ERO in natura e a apoptose, número de espermatozoides e número de leucócitos somente para o grupo Pacientes ${ }^{\mathrm{b}}$;

- correlação entre a medida de ERO in natura e a motilidade progressiva somente para o grupo Controle;

- correlação entre apoptose e número de espermatozoides nos grupos Pacientes e Pacientes $^{\mathrm{a}}$.

- correlação positiva da catalase e o número de leucócitos no grupo Pacientes, que se revelou uma característica particular do grupo Pacientes ${ }^{\mathrm{b}}$;

- correlação entre os AOPP e o número de leucócitos como uma característica das amostras de sêmen dos pacientes, com diferenças entre o padrão de correlação entre os grupos de pacientes com espermograma normal e com espermograma anormal;

- correlação positiva do número de leucócitos com a medida de ERO no sêmen in natura no grupo Pacientes ${ }^{\mathrm{b}}$ como característica particular deste grupo;

- O potencial de aplicação da medida dos AOPP como marcador de estresse oxidativo no sêmen;

- O potencial e a necessidade de uma análise sistemática entre os parâmetros relacionados com o espermograma e o estado redox entre pacientes e controles, bem como entre os parâmetros do mesmo paciente. 
8. Referências Bibliográficas 
Aebi H. Catalase in vitro. In: Packer, editor. Methods Enzymol, 105. New York: Academic Press. 1984;121-6.

Agarwal A, Ikemoto I, Loughilin KR. Effect of sperm washing on levels of reactive oxygen species in semen. Arch Androl. 1994;33:157-62.

Agarwal A, Ramadan A, Saleh MD. Role of oxidants in male infertility: rationale, significance and treatment. Urol Clin N Am. 2002;29:1-12.

Agarwal A, Saleh RA, Bedaiwy MA. Role of reactive oxygen species in the pathophysiology of human reproduction. Fertil Steril. 2003;79:829-43.

Agarwal A, Sekhon LH. Oxidative stress and antioxidants for idiopathic oligoasthenoteratospermia: is it justified? Indian J Urol. 2011;27:74-85.

Agarwal A, Hamada A, Esteves SC. Insight into oxidative stress in varicocele-associated male infertility: Part 1. Nat Rev Urol. 2012;9:678-90.

Agarwal A, Virk G1, Ong C1, du Plessis SS2. Effect of oxidative stress on male reproduction. World J Mens Health. 2014;Apr;32(1):1-17.

Agarwal A, Sharma RK, Sharma R, et al. Characterizing semen parameters and their association with reactive oxygen species in infertile men. Reprod Biol Endocrinol. 2014;May 7;12:33.

Aitken RJ, West K, Buckingham D. Leucocytic infiltration into the human ejaculate and its association with semen quality, oxidative stress, and sperm function. $J$ Androl. 1994;15:343-52.

Aitken RJ. Free radicals, lipid peroxidation and sperm function. Reprod Fertil Dev. 1995;7:659-68.

Aitken RJ, Fisher HM, Fulton N, et al. Reactive oxygen species generation by human spermatozoa is induced by exogenous NADPH and inhibited by the flavoprotein inhibitors diphenylene iodonium and quinacrine. Mol Reprod Dev. 1997;47:468-82.

Aitken RJ, Koopman P, Lewis SE. Seeds of concern. Nature. 2004;432:48-52. 
Aitken RJ, Baker MA, De Iuliis GN, Nixon B. New insights into sperm physiology and pathology. Handb Exp Pharmacol. 2010;198:99-115.

Aitken RJ, Baker MA. Causes and consequences of apoptosis in spermatozoa; contributions to infertility and impacts on development. Int J Dev Biol. 2013;57:265-72.

Alagozlu H, Gorgul A, Bilgihan A, Tuncer C, Unal S. Increased plasma levels of advanced oxidation protein products (AOPP) as a marker foroxidative stress in patients with active ulcerative colitis. Clin Res Hepatol Gastroenterol. 2013;37(1):80-5.

Angelopoulou R, Lavranos G, Manolakou P. ROS in the aging male: model diseases with ROS-related pathophysiology. Reprod Toxicol. 2009;28(2):167-71.

Alvarez JG, Sharma RK, Ollero $\mathrm{M}$, et al. Increased DNA damage in sperm from leukocytospermic semen samples as determinated by the sperm chromatin structure assay. Fertil Steril. 2002;78:319-29.

Athayde KS, Cocuzza M, Agarwal A et al. Development of normal reference values for seminal ROS and their correlation with leukocytes and semen parameters in a fertile population. J Androl. 2007;28:613-20.

Aziz, N., Saleh, R.A., Sharma, R.K. et al. Novel association between sperm reactive oxygen species production, sperm morphological defects, and the sperm deformity index. Fertil. Steril. 2004;81:349-54.

Bergendi L, Benes L, Duracková Z, et al. Chemistry, physiology and pathology of free radicals Life Sciences. 1999;65:1865-4.

Billing H, Furuta I, Rivier C, et al. Apoptosis in testis germ cells: developmental changes in gonadotropin dependence and localization to selective tubules stages. Endocrinol. 1995;136:5-12.

Cadenas E, Davies K J A. Mitochondrial free radicalgeneration, oxidative stress, and aging. Free Radic. Biol. Med. 2000;29:222-30.

Chabory E, Damon C, Lenoir A et al. Epididymis seleno-independent glutathione peroxidase 5 maintains sperm DNA integrity in mice. J Clin Invest. 2009;119:2074-85.

Chaurio RA, Janko C, Munoz LE, Frey B, Herrmann M, and Gaipl US. Phospholipids: key players in apoptosis and immune regulation. Molecules. 2009;14:4892-914. 
Cocuzza M, Athayde KS, Agarwal A et al. Age-related increase of reactive oxygen species in neat semen in healthy fertile men. Urology. 2008;71:491-4.

Colin et al. The effect of age on the expression of apoptosis biomarkers in human sprematozoa. Fertility and Sterility. 2010;94:2609-14.

De Lamirande E, Gagnon C. Human sperm hyperactivation and capacitation as parts of an oxidative process. Free Radic Biol Med. 1993;14:255-65.

De Lamirande E, Lamonthe G. Reactive oxygen-induced reactive oxygen formation during human sperm capacitation. Free Radic Biol Med. 2009;46:502-10.

Desai N, Sharma RK, Makker K et al. Physiologic and pathologic levels of reactive oxygen species in neat semen of infertile men. Fertility and Sterility. 2009;92(5):1626-31.

Desai N, Sabanegh E Jr, Kim T et al. Free radical theory of aging: implications in male infertility. Urology. 2010;75(1):14-9.

Ferreira ALA, Matsubara LS. Radicais livres: conceitos, doenças relacionadas, sistema de defesa e estresse oxidativo. Rev Assoc Méd Bras. 1997;43:1-16.

Fingerova H, Oborna I, Novotny $\mathrm{J}$ et al. The measurement of reactive oxygen species in human neat semen and in suspended spermatozoa: a comparison. Reprod Biol Endocrinol. 2009;7:118.

Freeman BA, Crapo JD. Biology of disease. Free radical and tissue injury. Laboratory Investigation. 1982;47:421-8.

Gavella M, Lipovac V. NADH-dependent oxidoreductase (diaphorase) activity and isoenzyme pattern of sperm in infertile men. Arch Androl. 1992;28:35-41.

Gharagozloo P, Aitken RJ. The role of sperm oxidative stress in male infertility and the significance of oral antioxidant therapy. Hum Reprod. 2011;26:1628-40.

Haddad JJ.Antioxidant and prooxidant mechanisms in the regulation of redox (y)-sensitiv transcription factors. Cellular Signalling. 2002;14:879-97. 
Halliwell B, Gutteridge JMC. Role of free radicals and catalytic metal ions in human disease: an overwiew. Methods in Enzymology. 1990;186:1-85.

Halliwell B, Gutteridge JMC. Free radicals in biology and medicine. New York: Oxford University Press. 1999;936.

Hamada AJ, Montgomery B, Agarwal A. Male infertility: a critical review of pharmacologic management. Expert Opin Pharmacother. 2012;13:2511-31.

Hampl R, Drábková P, Kand'ár R, Stěpán J. Impact of oxidative stress on male infertility. Ceska Gynekol. 2012;77:241-5.

Hellani A, Al-Hassan S, Iqbal MA et al. Y chromosome microdeletions in infertile men with idiopathic oligo- or azoospermia J Exp Clin Assit Reprod. 2006;3:1-6.

Henkel RR. Leukocytes and oxidative stress: dilemma for sperm function and male fertility. Asian J Androl. 2011;13:43-52.

Kalousová M, Zima T, Tesar V et al. Advanced glycoxidation end products in chronic diseases-clinical chemistry and genetic background. Mutat Res. 2005;11;579(1-2):37-46.

Kesari KKB: J. Effects of microwaves at $2.45 \mathrm{GHz}$ radiations on reproductive system of male rats. Toxicological \& Environmental Chemistry. 2010;92:1135-47.

Khosrowbeygi, A., Zarghami, N. Levels of oxidative stress biomarkers in seminal plasma and their relationship with seminal parameters. BMC Clin. Pathol. 2007;7:6.

Kimberly L, Case A, Cheung AP et al. Advanced reproductive age and fertility: No. 269, November 2011.Int J Gynaecol Obstet. 2012;117:95-102.

Kovac JR, Pastuszak AW, Lamb DJ. The use of genomics, proteomics, and metabolomics in identifying biomarkers of male infertility. Fertil. Steril. 2013;99:998-1007.

Lahorte CM, Vanderheyden JL, Steinmetz N, Van de Wiele C, Dierckx RA, and Slegers G. Apoptosis-detecting radioligands: current state of the art and future perspectives. Eur $\mathbf{J}$ Nucl Med Mol Imaging. 2004;31:887-919. 
Lackner J, Schatzl G, Horvath S et al. Value of counting white blood cells (WBC) in semen samples to predict yhe presence of bacteria. Eur Urol. 2006;49:148-52.

Lanzafame FM, La Vignera S, Vicari E, Calogero AE. Oxidative stress and medical antioxidant treatment in male infertility. Reprod Biomed Online. 2009;19:638-59.

Masella R., Di Benedetto R., Vari R., Filesi C., \& Giovannini C. Novel mechanisms of natural antioxidant compounds in biological systems: Involvement of glutathione and glutathione related enzymes. J Nutr Biochem. 2005;16:577-86.

McCord JM, Fridovich I. Superoxide dismutase. An enzimic function for erythrocuprein (hemocuprein). Journal of Biological Chemistry. 1969;244:6049-55.

Moein MR, Vahidi S, Ghasemzadeh J, Tabibnejad N. Comparison of reactive oxygen species in neat and washed semen of infertile men. Iran J Reprod Med. 2014; May;12(5):301-6.

Nogueira CW, Zeni G, \& Rocha JBT. Organoselenium abd organotellurium compounds: Toxicology and Pharmacology. Chem Rev. 2004;104:6255-85.

Nordberg J, Arnér ESJ. Reactive oxygen species, antioxidants and the mammalian thioredoxin system. Free Radic Biol Med. 2001;31:1287-12.

Oosterhuis GJ, Mulder AB, Kalsbeek-Batenburg et al. Measuring apoptosis in human spermatozoa: a biological assay for semen quality? Fertil Steril. 2000;74:245-50.

Pasqualotto FF, Sharma RK, Potts JM et al. Seminal oxidative stress in patients with chronic prostatitis. Urology. 2000;55:881-5.

Pasqualotto FF, Sharma H, Kobayashi D et al. Oxidative stress in normospermic men undergoing infertility evaluation. J Androl. 2001;22:316-22.

Piwowar A, Knapik-Kordecka M, Warwas M. Comparison of the usefulness of plasma levels of oxidatively modified forms of albumin in estimating kidney dysfunction in diabetic patients. Clin Invest Med. 2010;1:33(2):09.

Plante M, De Lamirande E, Gagnon C. Reactive oxygen species released by activated neutrophils, but not by deficient spermatozoa, are sufficient to affect normal sperm motility. Fertil Steril. 1994;62:387-393. 
Rao B, Souflir JC, Martin M, David G. Lipid peroxidation in human spermatozoa as related to midpiece abnormalities and motility. Gamete Res. 1989;24:127-34.

Rengan AK, Agarwal A, van der Linde M, du Plessis SS. An investigation of excess residual cytoplasm in human spermatozoa and its distinction from the cytoplasmic droplet. Reprod Biol Endocrinol. 2012;10:92.

Saalu, L.C. The incriminating role of reactive oxygen in idiopathic male infertility: An evidence based evaluation. Pakistan Journal of Biological Sciences. 2010;13(9):413-22.

Said TM et al. Role of caspases in male infertility. Human Reprod Update. 2004;10:39-51.

Sakkas D, Mariethoz E, Manicardi G, Bizzaro D, Bianchi PG, Bianchi U. Origino f DNA damage in ejaculated human spermatozoa. Rev Reprod. 1999;4:31-37.

Saleh RA, Agarwal A. Oxidative stress and male infertility: from research bench to clinical practice. J Androl. 2002a;23:737-52.

Saleh RA, Agarwal A, Sharma RK, Nelson DR, Thomas AJ Jr. Effect of cigarette smoking on levels of seminal oxidative stress in infertile men: a prospective study. Fertil Steril. 2002b; 78:491-9.

Saleh RA, Agarwal A, Nada EA, El-Tonsy MH, Sharma RK, Meyer A, et al. Negative effects of increased sperm DNA damage in relation to seminal oxidative stress in men with idiopathic and male factor infertility. Fertil Steril. 2003;79Suppl 3:1597-605.

Sanocka D, Kurpisz M. Reactive oxygen species and sperm cells. Reprod Biol Endocrinol. 2004;2:12.

Selmeci L, Seres L, Antal M, et al. Advanced oxidation protein products (AOPP) for monitoring oxidative stress in critically ill patients: a simple, fast and inexpensive automated technique. Clin Chem Lab Med. 2005;43(3):294-7.

Selmeci L.Advanced oxidation protein products (AOPP): novel uremic toxins, or components of the non-enzymatic antioxidant system of the plasma proteome? Free Radic. 2011;45(10):1115-23. 
Sharma RK, Pasqualotto AE, Nelson DR, et al. Relationship between seminal white blood cell counts and oxidative stress in men treated at an infertility clinic. J Androl. 2001;22:575-83.

Shekarriz M, Sharma RK, Thomas AJ Jr, Agarwal A. Positive myeloperoxidase staining (Endtz test) as an indicator of excessive reactive oxygen species formation in semen. $\mathbf{J}$ Assist Reprod Genet. 1995;12:70-4.

Sies H. Oxidative stress. 1985;507.

Stewart AF, Kim ED:Fertility concerns for the aging male.Urology. 2011;78:496-499.

Sukcharoen N, Deith J, Irvine DS et al. Predicting the fertilizing potential of human sperm suspensions in vitro: Importance of sperm morphology and leukocyte contamination. Fertil Steril. 1995;63:1293-300.

Thiele JJ, Friesleben HJ, Fuchs J, Ochsendorf FR. Ascorbic acid and urate in human seminal plasma: determination and interrelationships with chemiluminescence in washed semen. Hum Reprod. 1995;10:110-15.

Thomas J, Fishel SB, Hall JA, et al. Increased polymorphonuclear granulocytes in seminal plasma in relation to sperm morphology. Hum Reprod. 1997;12:2418-21.

Tremellen K. Oxidative stress and male infertility--a clinical perspective. Hum Reprod Update. 2008;14:243-58.

Trussell JC. Optimal diagnosis and medical treatment of male infertility. Semin Reprod Med. 2013;31:235-6.

Turrens JR, Boveris A. Generation of superoxide anion by NADH dehydrogenaseof bovine heart mitochondria. The Biochemical Journal. 1980;191:421-7.

Valko M, Leibtriz D, Moncol J et al. Free radicals and antioxidantes in normal physiological functions and human diasease. The International Journal of Biochemistry \& Cell Biology. 2007;39:44-84.

Venkatesh S, Riyaz AM, Shamsi MB et al. Clinical significance of reactive oxygen species in semen of infertile indian men. Andrologia. 2009;41:251-6. 
Wang X, Sharma RK, Gupta A, et al. Alterations in mitochondria membrane potential and oxidative stress in infertile men: a prospective observational study. Fertil Steril. 2003;80Suppl 2:844-50.

Warren JS, Johnson KJ, Ward PA.Oxygen radical in cell injury and cell death. Pathol Immunopathol Res. 1987;6:301-15.

WHO 2010. World Health Organization laboratory manual for the examination and processing of human semen - 5th ed.

Wiser, H.J., Sandlow, J., Ko“hler, T.S. Causes of male infertility. In: Parekattil, S.J., Agarwal, A. (Eds.), Male Infertility: Contemporary Clinical Approaches, Andrology, ART and Antioxidants. Springer Science+Business Media. 2012.

Witko-Sarsat V, Friedlander M, Capeillère-Blandin C et al. Advanced oxidation protein products as a novel marker of oxidative stress in uremia. Kidney Int. 1996; 49(5):1304-13.

Witko-Sarsat V, Friedlander M, Capeillère-Blandin C, Nguyen-Khoa T et al. Advanced oxidation protein products as a novel marker of oxidative stress in uremia. Kidney Int. 1996;49(5):1304-13.

Zini A, Garrels K, Phang D. Antioxidant activity in the semen of fertile and infertile men. Urology. 2000;55:922-26.

Zini A, San Gabriel M, Libman J. Lycopene supplementationin vitro can protect human sperm deoxyribonucleic acid from oxidative damage. Fertil Steril. 2010; 94:1033-6. 
Anexos 
ANEXO A

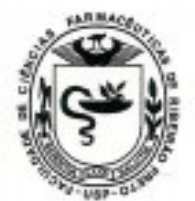

\title{
UNIVERSIDADE DE SĀO PAULO \\ Faculdade de Clências Farmacéuticas de Ribeirão Preto \\ COWTE DE ENCA EM PESQUSA
}

Of. CEP/FCFRP n ${ }^{\circ}, 031 / 2013$

kms

Ribeirăo Preto, 13 de junho de 2013.

\author{
À Pós-graduanda \\ Adriana Patrícia Laurenti Coelho \\ Orientadora: Prof ${ }^{\mathrm{a}}$. $\mathrm{Dr}^{4}$. Cleni Mara Marzocchi Machado \\ FCFRP/USP
}

Prezadas Pesquisadoras,

Informamos que o Comitê de Etica em Pesquisa da FCFRP/USP aprovou, em sua $115^{a}$ reunião ordinária realizada em 02.05 .2013 , o projeto de pesquisa intitulado "AVALLAÇÃO DO ESTADO REDOX NO SĖMEN HUMANO E SUA CORRELACÃO COM OS PARAMETROS DO ESPERMOGRAMA", apresentado por VosSa Senhoria a este Comite, Protocolo CEP/FCFRP n ${ }^{\circ}, 294$.

Informamos que, conforme Carta Circular 003/2011 da CONEP (Comissăo Nacional de Ética em Pesquisa), o sujeito de pesquisa ou seu representante, quando for o caso e também o pesquisador responsável deverăo rubricar todas as páginas do Termo de Consentimento Livre e Esclarecido - TCLE, apondo sua assinatura na última página do referido Termo. Ainda, de acordo com a Resolução 196/96, item IV.2, letra d, "o TCLE deverá ser elaborado em duas vias, sendo uma retida pelo sujeito da pesquisa ou por seu representante legal e uma arquivada pelo pesquisador".

Em atendimento à Resolução 196/96, lembramos que deverá ser encaminhado ao CEP o relatório final da pesquisa em formulário próprio deste Comitê, bem como comunicada qualquer alteração, intercorrência ou interrupcão do mesmo, tais como eventos adversos e eventuais modificaçóes no protocolo ou nos membros da equipe.

Atenciosamente,

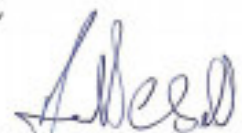

PROF, DR. HARNOLDO COLARES COELHO CEP/FCFRP

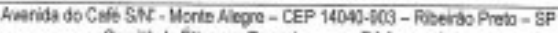

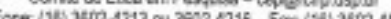


Projeto de pesquisa: "Avaliação do estado redox no sêmen humano e sua correlação com os parimetros do espermograma "

Pesquisador responsável: Adriana Patrícia Laurenti Coelho

Orientadora: Prof. Dr'. Cleni Mara Marzocchi Machado

Instituiçâo Proponente: Faculdade de Ciências Farmacêuticas de Ribeirão Preto - USP

"O CEP do HC e da FMRP-USP concorda com o parecer ético emitido pelo CEP da Instituição Proponente, que cumpre as Resoluções Éticas Brasileiras, em especial a Resolução CNS 196/96. Diante disso, o HCFMRP-USP, como instituiçalo co-participante do referido projeto de pesquisa, está ciente de suas co-responsabilidades e de seu compromisso no resguardo da segurança e bemestar dos sujeitos desta pesquisa, dispondo de infra-estrutura necessária para a garantia de tal segurança e bem-estar.

Clente e de acordo:

\section{Sharciadillanove}

$\mathrm{Dr}^{\mathrm{a}}$ Marcia Guimarães Villanova Coordenadora do Comite de Ėtica em Pesquisa - HCFMRP-USP
Prof. Dr. José Alexandre de Souza Crippa Coordenador Jecnico Científico da Unidade de Pesquisa Clínica - HCFMRP-USP

\section{de} Campus Universitario - Mons Alage
$14046-900$ Riberso Preto SP
Comte de Elica im Pasquiss do HCAP e FMRP.USP FWA -06002733: IRB-60002165 Pegistro Plataforma BrasiCONEP $\pi^{\circ} 5440$ (016) $3802 \cdot 2228$

www.hcrp.usp.br
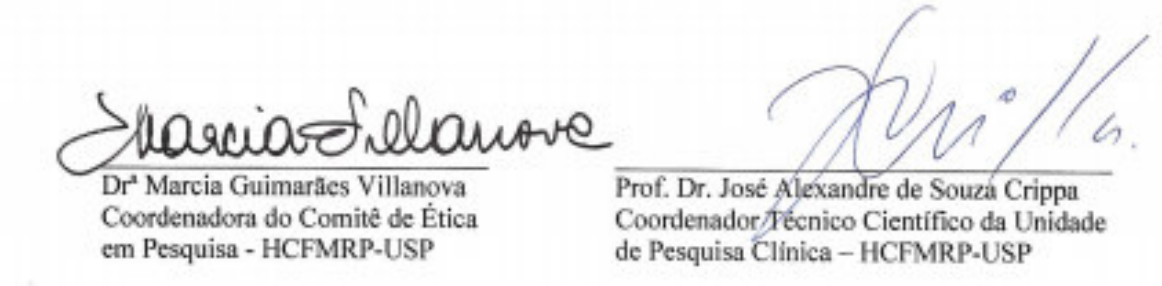
ANEXO B

1 Solução para quimioluminescência

\section{Luminol 5mM}

Solução 1

$\begin{array}{lr}\text { Luminol } & 1,77 \mathrm{mg} \\ \text { DMSO } & 95,88 \mu \mathrm{L}\end{array}$

Solução 2

Solução 1

$10 \mu \mathrm{L}$

Hanks

$190 \mu \mathrm{L}$

\section{Solução balanceada de Hanks}

\begin{tabular}{ll}
\hline $\mathrm{NaCl}$ & $8 \mathrm{~g}$ \\
$\mathrm{KCl}$ & $0,4 \mathrm{~g}$ \\
$\mathrm{CaCl}_{2}$ anidro & $0,139 \mathrm{~g}$ \\
$\mathrm{MgCl}_{2} .6 \mathrm{H}_{2} \mathrm{O}$ & $0,1 \mathrm{~g}$ \\
$\mathrm{MgSO}_{4} .7 \mathrm{H}_{2} \mathrm{O}$ & $0,1 \mathrm{~g}$ \\
$\mathrm{Na}_{2} \mathrm{HPO}_{4}$ & $0,06 \mathrm{~g}$ \\
$\mathrm{Glicose}$ & $1,0 \mathrm{~g}$ \\
$\mathrm{NaHCO} 3$ & $0,35 \mathrm{~g}$ \\
Água deionizada qsp & $1000 \mathrm{~mL}$ \\
\hline & \\
\hline & Ajustar o pH final para $7,2 \mathrm{a} 25^{\circ} \mathrm{C} \mathrm{com} \mathrm{NaOH}$. \\
Filtrar.
\end{tabular}


PBS (Salina Tamponada com Fosfato) pH 7,4 (10x)

\begin{tabular}{lc}
\hline $\mathrm{NaCl}$ & $80,0 \mathrm{~g}$ \\
$\mathrm{KCl}$ & $2,0 \mathrm{~g}$ \\
$\mathrm{Na}_{2} \mathrm{HPO}_{4}$ & $11,5 \mathrm{~g}$ \\
$\mathrm{KH}_{2} \mathrm{PO}_{4}$ & $2,0 \mathrm{~g}$ \\
Água deionizada estéril qsp & $1000 \mathrm{~mL}$ \\
\hline
\end{tabular}

Ajustar $\mathrm{pH}$ final para 7,4 a $25^{\circ} \mathrm{C}$ com $\mathrm{HCl}$

2 Solução para catalase

Tampão Fosfato 50mM pH - 7,4

\section{Solução A}

$\mathrm{KH}_{2} \mathrm{PO}_{4} \quad 1,7025 \mathrm{~g}$

Água deionizada qsp $\quad 250 \mathrm{~mL}$

\section{Solução B}

$\mathrm{Na}_{2} \mathrm{HPO}_{4}$ anidro

$2,789 \mathrm{~g}$

Água deionizada qsp

$250 \mathrm{~mL}$

Misturar $150 \mathrm{~mL}$ da solução A e $250 \mathrm{~mL}$ da solução B e ajustar o pH com $\mathrm{HCl}$. 
Peróxido de Hidrogênio 16mM

\begin{tabular}{ll}
\hline $\mathrm{H}_{2} \mathrm{O}_{2} 30 \%$ & $54 \mu \mathrm{L}$ \\
Tampão Fosfato 50mM & $100 \mathrm{~mL}$ \\
& \\
\hline
\end{tabular}

Manter ao abrigo da luz.

3 Solução para TBARS

TBA

\begin{tabular}{ll}
\hline TBA & $0,67 \mathrm{~g}$ \\
$\mathrm{NaOH}$ & $0,5 \mathrm{~g}$ \\
Ácido acético glacial & $100 \mathrm{~mL}$ \\
\hline
\end{tabular}

4 Solução para contagem de leucócitos

\begin{tabular}{ll}
\multicolumn{2}{c}{ Benzidina 0,125\% } \\
\hline \multicolumn{2}{c}{ Solução Estoque } \\
Etanol 96\% & $25 \mathrm{~mL}$ \\
Benzidina & $0,0625 \mathrm{~g}$ \\
Água deionizada & $25 \mathrm{ml}$
\end{tabular}

Solução de trabalho

Solução estoque $\quad 4,0 \mathrm{~mL}$

$\mathrm{H}_{2} \mathrm{O}_{2} 3 \% \quad 50 \mu \mathrm{L}$

Manter ao abrigo da luz. 